\title{
ADSORÇÃO DE BSA EM SISTEMA CRIOGEL DE TROCA IÔNICA
}

\author{
A. CLAUDINO ${ }^{1}$, A. C. GOMES ${ }^{1}$, R. F. CANO ${ }^{1}$, W. F. S. JÚNIOR ${ }^{1}$, S. L. DA SILVA ${ }^{2}$, \\ A. H. TÓTOLA ${ }^{2}$, B. M. A. de CARVALHO \\ 1 Universidade Federal de São João del-Rei, Graduandos em Engenharia de \\ Bioprocessos \\ 2 Universidade Federal de São João del-Rei, Departamento de Engenharia de \\ Bioprocessos, Química e Biotecnologia \\ E-mail para contato: brunamara.carvalho@gmail.com
}

\section{RESUMO}

Monólitos de criogéis supermacroporosos são suportes eficazes na separação em processos downstream. Neste contexto, criogel de poliacrilamida de troca iônica (IE) foi preparado com o objetivo de adsorver a proteína BSA (bovine serum albumin). A matriz de criogel foi caracterizada por medidas de capacidade de inchamento, porosidade e capacidade de troca iônica. A modelagem dos dados para as amostras de BSA no sistema Criogel-IEC foi analisada usando dados de equilíbrio adsortivo para o modelo de Langmuir. Os resultados experimentais mostraram porosidade em torno de 0,2841, capacidade de inchamento em torno de 13,38 e capacidade de troca iônica de $825 \mu \mathrm{mol}$ gat/g. Os resultados de adsorção apresentaram uma boa resposta de interação entre o sistema criogel-IEC com a proteína BSA. O modelo de Langmuir foi ajustado de maneira satisfatória, mostrando sim, a sua aplicabilidade em prever comportamentos de equilíbrio adsortivo em sistemas líquido-solido. A matriz de criogel-IEC apresenta-se como uma tecnologia promissora na área de bioseparações.

\section{INTRODUÇÃO}

Uma grande porcentagem do soro de leite produzido pelas indústrias de laticínios é descartada sem nenhum tratamento nos corpos de água, o que gera sérios impactos ambientais. $\mathrm{O}$ soro é fonte de proteínas e peptídeos funcionais $(0,7 \% \mathrm{~m} / \mathrm{m})$, lipídeos $(0,1 \% \mathrm{~m} / \mathrm{m})$, vitaminas $(0,1 \% \mathrm{~m} / \mathrm{m})$, minerais $(0,5 \% \mathrm{~m} / \mathrm{m})$ e lactose $(4,9 \% \mathrm{~m} / \mathrm{m})$ Zadow (2006). Em torno de 15 a $20 \%$ do conteúdo proteico do soro de leite é composto por BSA.

A BSA é uma proteína proveniente do soro de queijo. Conta com a presença de 17 pontes dissulfeto na molécula, sendo que o rompimento dessas ligações resulta em modificações de algumas de suas propriedades físicas e estruturais e do perfil de solubilidade em função do pH. (Zadow, 2006).

Criogéis, géis poliméricos sintetizados em condições criogênicas, tem se tornado uma tecnologia muito útil na área de bioseparação, como em processamento de proteínas, vírus, entre outros. Isso acontece devido ao fato de que as condições criogênicas conferem a eles um sistema contínuo de macroporos interconectados com variação de tamanho de 10-100 $\mu \mathrm{m}$, uma baixa resistência ao escoamento e uma difusão desobstruída de solutos de qualquer tamanho, fatores que os 


\section{9 a 22 de outubro de 2014 \\ Florianópolis/SC}

tornam um tipo de fase estacionária muito atrativa para cromatografia (LOZINSKY et al, 2008).

O trabalho teve como objetivo produzir e caracterizar resinas supermacroporosas de criogel trocadora de íons e avaliar o processo de adsorção da proteína BSA em tais resinas.

\section{MATERIAIS E MÉTODOS}

\subsection{Materiais}

Acrilamida (AAm, 99,9\%), N,N'-Metilenobisacrilamida (MBAAm, 99\%), N,N- N, 2Dimetilaminoetil Metacrilato (DMAEMA, \%), Per-sulfato de Amônio (APS, 98\%), N,N,N',N'Tetrametil-etilenodiamina (TEMED, 99\%).

\subsection{Síntese da matriz de IEC}

A produção da matriz de criogel foi desenvolvida de acordo com a metodologia de Arvidsson et al. (2002), segundo as seguintes modificações: dissolução de 4,21 g de AAm, 1,87 g de MBAAM e $1 \mathrm{~mL}$ de DMAEMA em $100 \mathrm{~mL}$ de água Mili-Q e desgaseificação desta solução em ultrassom por 5 ciclos de 1min; ajustou-se o pH entre 6,3 - 6,8 com $\mathrm{HCl} 1 \mathrm{M}$; adicionou-se de $90 \mu \mathrm{L}$ de TEMED em seguida, homogeneizou-se a solução e levou-a para o banho de gelo por 5 minutos; foi acrescentado $288 \mathrm{mg}$ de APS. Injetou-se $10 \mathrm{~mL}$ da solução reacional em seringas, vedou-as e as amostras foram mantidas em banho ultratermostático a $-12^{\circ} \mathrm{C}$ por $5 \mathrm{~h} \mathrm{e}-15^{\circ} \mathrm{C}$ overnight. Por fim, lavou-se cada resina com $50 \mathrm{~mL}$ água deionizada sob vazão de $1 \mathrm{~mL} / \mathrm{min}$.

\subsection{Caracterização das Matrizes}

Capacidade de Inchamento: A capacidade de inchamento do criogel (Sw/w) foi determinada por meio da imersão das matrizes em recipientes contendo água por um intervalo de $2 \mathrm{~h}$. A cada 15 min os recipientes foram agitados manualmente e de forma lenta. Em seguida, retirou-se o excesso de água das matrizes e, então, obteve-se o peso úmido (mw) das mesmas. As matrizes foram secas a $60^{\circ} \mathrm{C}$ até peso constante, as massas das amostras secas (md) foram determinadas e a capacidade de inchamento foi calculada pela Equação 1:

$\mathrm{S}_{\mathrm{w} / \mathrm{w}}=\frac{\left(\mathrm{m}_{\mathrm{w}}-\mathrm{m}_{\mathrm{d}}\right)}{\mathrm{m}_{\mathrm{d}}}$

Onde $\mathrm{S}_{\mathrm{w} / \mathrm{w}}$ é a capacidade de inchamento $\left(\mathrm{g} \mathrm{H}_{2} \mathrm{O} / \mathrm{g}\right.$ de gel seco) e $\mathrm{m}_{\mathrm{w}}$ e $\mathrm{m}_{\mathrm{d}}$ são as massas $(\mathrm{g}) \mathrm{da}$ amostra em peso úmido e seco, respectivamente.

Porosidade: a porosidade do monólito de criogel foi avaliada de acordo com o procedimento relatado em Yao et al. (2006) e, então, calculada segundo a Equação 2

$\varphi=\frac{\left(\mathrm{m}_{\mathrm{w}}-\mathrm{m}_{\mathrm{s}}\right)}{\rho_{\mathrm{w}} \mathrm{V}_{0}}$

\subsection{Experimentos de troca-iônica}

A matriz de criogel IEC $(10 \mathrm{~mL})$, seca a $60^{\circ} \mathrm{C}$ até peso constante, foi cortada em pequenos pedaços, sendo transferida para um béquer, o qual continha uma mistura de $40 \mathrm{~mL}$ de $\mathrm{HCl} 0,1 \mathrm{M}$ e 15 $\mathrm{mL}$ de solução saturada de $\mathrm{NaCl}$. A mistura foi mantida à temperatura ambiente durante 24 horas, com agitação periódica. Em seguida, foi titulada com $\mathrm{NaOH}$ 0,1M até pH 6,9-7,3 em agitação lenta. Um branco contendo uma mistura de $40 \mathrm{~mL}$ de $\mathrm{HCl} 0,1 \mathrm{M}$ e $15 \mathrm{~mL}$ de solução saturada de $\mathrm{NaCl}$ foi titulada até ao mesmo valor de $\mathrm{pH}$.

Titulação dos grupos amino terciários: foi realizada de acordo com Staby et al. (2000). Através 
de uma coluna de IEC foi bombeado $50 \mathrm{~mL}$ de $\mathrm{KCl}$ 1,0M, pH 3,0 a uma taxa de fluxo de $1 \mathrm{~mL} / \mathrm{min}$. Em seguida, a matriz IEC criogel foi retirada da coluna, cortada em pequenos pedaços e transferindoos para um béquer contendo $40 \mathrm{~mL}$ de $\mathrm{KCl}$ 1,0M, $\mathrm{pH} 3,0$. A mistura foi titulada com solução de $\mathrm{NaOH} 0,1 \mathrm{M}$ até pH 12. Uma solução em branco (40 mL 1,0M de $\mathrm{KCl}, \mathrm{pH} \mathrm{3,0}$ ) foi titulada em relação ao mesmo intervalo de $\mathrm{pH}$.

\section{RESULTADOS E DISCUSSÃO}

\subsection{Produção do criogel}

As matrizes de criogel obtidas apresentaram-se como um monólito esponjoso, como mostrado na Figura 1. Estes resultados estão de acordo com os observados por Carvalho et al., 2014 ao avaliarem o processo de adsorção da proteína Lactoferrina em colunas supermacroporosas de criogel.

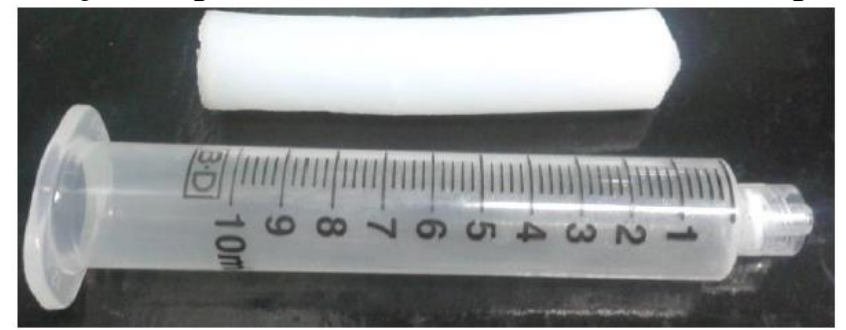

Figura 1 - Coluna supermacroporosa de criogel de troca iônica.

\subsection{Caracterização do criogel}

Os dados obtidos após a caracterização do monólito são apresentados na Tabela 1.

Tabela 1 - Parâmetros da caracterização do matriz de criogel sintetizado

\begin{tabular}{cccccccccc}
\hline \hline $\mathbf{M}_{\mathbf{d}}(\mathbf{g})$ & $\mathbf{M}_{\mathrm{w}}(\mathbf{g}) \mathbf{S}_{\mathrm{w} / \mathrm{w}}$ & $\mathbf{M}_{\mathrm{d}}(\mathbf{g}) \boldsymbol{\varphi}$ & $\mathbf{M}_{\mathbf{s}}(\mathbf{g}) \boldsymbol{\varphi}$ & $\mathbf{M}_{\mathrm{w}}(\mathbf{g}) \boldsymbol{\varphi}$ & $\mathbf{V}_{\mathbf{1}}(\mathbf{m L})$ & $\mathbf{V}_{\mathbf{2}}(\mathbf{m L})$ & $\mathbf{V}_{\mathbf{0}}(\mathbf{m L})$ & $\mathbf{S}_{\mathrm{w} / \mathrm{w}}(\boldsymbol{\%})$ & $\mathbf{\Phi ( \% )}$ \\
\hline 0,1104 & 1,5452 & 0,11455 & 0,9471 & 1,5328 & 15 & 15,375 & 0,375 & 13,3828 & 28,41
\end{tabular}

As matrizes de criogel apresentaram com boa capacidade de inchamento e porosidade. Os resultados apresentados estão de acordo com os encontrados por Arvidsson et al., 2002.

\subsection{Capacidade de adsorção}

A matriz apresentou uma capacidade de troca-iônica alta, sendo esta de $825 \mu \mathrm{mol}$ gat $/ \mathrm{g}$. A titulação do monólito resultou na curva de titulação da Figura 2. O desenvolvimento da matriz de troca iônica pertence ao tipo fraco de troca aniônica. A curva de titulação da solução salina (Branco) é apresentada para tal comparação. Os resultados encontrados estão de acordo com os encontrados por Arvidsson et al., 2002. 


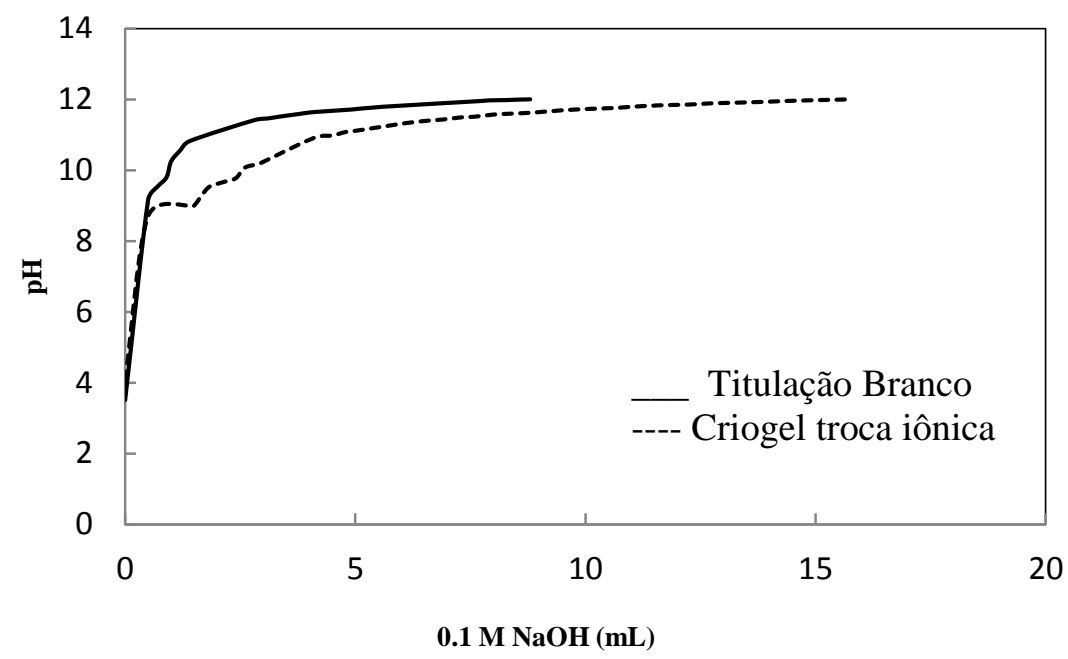

Figura 2 - Gráfico da curva de titulação dos aminos terciários.

\section{CONCLUSÃO}

A matriz de criogel de troca iônica foi produzida e caracterizada. Os resultados encontrados neste trabalho estão de acordo com os encontrados em literaturas. A matriz de criogel mostrou-se eficiente na capacidade de troca-iônica, sendo que os resultados obtidos para a adsorção apresentaram boa resposta de interação entre o sistema criogel-IEC com a proteína BSA.

\section{REFERÊNCIAS}

ARVIDSSON, P, PLIEVA, F.M, SAVINA, I.N, LOZINSKY, V.I, FEXBY, S, BÜLOW, L, GALAEV, I.Y, MATTIASSON, B. Chromatography of microbial cells using continuous supermacroporous affinity and ion-exchange columns. J. Chromatogr. A 977:27-38, 2002.

CARVALHO, B.M.A, et al. Direct capture of lactoferrin from cheese whey on supermacroporous column of polyacrylamide cryogel with copper ions. Food Chemistry 154:308-314, 2014.

LOZINSKY, V. I. Polymeric cryogel as a new family of macroporous and supermacroporous materials for biotechnological purposes, Russian Chemical Bulletin, International Edition, Vol. 57, No. 5, p. 1015-1032, 2008.

NELSON, David L.; COX, Michael M. Princípios de bioquímica de Lehninger. 5.ed. Porto Alegre: ArtMed, p. 173-181, 2011.

YAO, K.; YUN, J.; SHEN, S.; WANG, L.; HE, X.; YU, X. Characterization of a novel continuous supermacroporous monolithic cryogel embedded with nanoparticles for protein chromatography. Journal of Chromatography A, 1109, 103-110, 2006.

ZADOW J. G., Utilization of milk components: Whey. In R. K. Robinson (Ed.), Modern dairy technology, advances in milk processing, Vol. 1 (2nd ed.) 313 373. London, UK: Chapman \& Hall, 1996. 